\section{Advising the government}

SIR-John Maddox is correct (Nature 330, $515 ; 1987)$ in emphasizing the interdisciplinary complexity of arms control issues that has led to a need for "more intellectual adventurousness"; the very complexity of these issues indicates the need to create interdisciplinary centres such as Stanford University's Center for International Security and Arms Control. In fact, the Stanford Center has grown with the conviction that a balanced mix of scholars, practitioners and students from many disciplines is needed to generate the new ideas and to train students in national security planning, of which arms control is one important part.

I regret, therefore, that Maddox suggests that I or my colleagues view the Stanford Center as one that simply "exists to replace the generation of natural scientists who have given valiant public service in the cause of arms control during the past three decades". He badly misses the mark by focusing on only one aspect of our activities. National security planning is a field of political action and, as Albert Einstein once said, "politics is much harder than physics". But when political leaders set policy goals and act, they must do so on the basis of informed technical data and projections of future technical possibilities. Policy goals cannot coerce laws of nature. President Reagan's poorly conceived Strategic Defense Initiative (SDI) is a case in point.

It has become painfully clear in the subsequent debate that there is a need for a cadre of technical experts trained and utilized to provide an informed and independent input into such issues which, although essentially political, must rest firmly on an understanding of technological reality.

During the $1960 \mathrm{~s}$ and into the early 1970s, the President's Science Advisory Committee, through its working panels, helped to train such a cadre. Today, after a 15-year lapse, the United States needs a new generation of informed, technically expert and independent scientists to serve that function. The Stanford Center will be making a valuable contribution if it can help fill that need as one of its research and teaching activities.

More broadly, the United States needs to recreate an effective presidential science advisory mechanism. Many of the early unrealistic claims for SDI (some still occasionally heard) could have been avoided had such a mechanism been in place. Here again, Maddox misses the point in characterizing the debate of the past four years as lacking the "excitement of earlier decades".

As one who has participated in both the 1969-72 and the 1983-87 debates on antiballistic missile systems, I disagree com- pletely. There have been a number of independent, thorough and well-informed studies on strategic defence, involving a large number of academic and industrial scientists. These have been mostly carried on outside government and have played an important role in the public debate witness the recent study by the American Physical Society, which clearly discusses the technical challenge of directed energy weapons for strategic defence.

Just because of the vacuum created by the demise of effective scientific advisory channels in government, independent studies have played a very important role in informing the SDI debate - and at a high level of scientific sophistication and intensity.

The recent Intermediate Nuclear Force agreement has created still more difficult technical challenges. Indeed, Maddox is right in saying that on-site cooperative measures of inspection are very difficult political issues. However, the need for scientists to contribute here will in no way be diminished. Unless Maddox knows something that I do not, it will take clever analysis if the verifiers are to be able to say with confidence and substance that specific agreements can indeed be verified.

Sidney D. DRELl

Stanford Linear Accelerator Center,

Stanford University, PO Box 4349,

Stanford, California 94305, USA

\section{Directing science}

SIR-In the many letters written about the Advisory Board for the Research Counils (ABRC) report of July 1987 on $A$ Strategy for the Science Base, there has been little discussion about which people or organizations should be involved in the future direction of science. Most of the discussion has been focused on what those directions should be and where the research should be concentrated. In its written response to the $\mathrm{ABRC}$, the Institute of Mathematics and its Applications (IMA), among other comments (to be published in the IMA Bulletin), made a point of first welcoming the open discussion by ABRC, and then asking it to pursue this policy of openness in future. Policy decisions from the strategic down to the lowest grantgiving levels in the research councils are arrived at largely in secret and with very little open discussion before or after the decisions. For example, new policy instructions by the Science and Engineering Research Council mathematics committee are never discussed with mathematical societies, and the same goes generally (but not always) for other committees.

The IMA strongly believes that the scientific, technological and engineering institutions should be involved in consultations both before and after changes in science policy. Such consultation need not be lengthy, but should be an open process.

Most outside advice is at present given by individuals: there is little encouragement for organizations to discuss internally these policy questions and then give advice as organizations. Concerned advice given by a group may (though not always) contain more and better ideas than those of individuals. As UK scientific and technological organizations, such as the IMA, have a wide membership in research, industry and government establishments, their voices should be heard. They could provide a useful and innovative input as, for example, the institute's response to the Advisory Council for Applied Research and Development where advice on computer verification was given. They could make a particularly valuable contribution in multidisciplinary policy questions.

The IMA believes that it and other scientific institutions could play a useful role in informing their own members in academic life, industry and government establishments about science policy decisions and their implementation. The institutions already play a valuable role in organizing conferences, workshops and short courses on subject areas that the research councils are encouraging, and this could be increased.

R. F. Churchhouse (President)

The Institute of Mathematics and its Applications,

Maitland House, Warrior Square, Southend-on-Sea, Essex SS1 2JY, UK

\section{Time for secrecy}

SIR-In his review of Geoffrey Cannon's book The Politics of Food, John Rivers (Nature 238, 769; 1987) suggests that in Britain the time of day will soon be an official secret. I am not sure that this hasn't happened already. Precise timekeeping has become one of the cornerstones of modern military technology. In the United States for instance, the Naval Observatory has responsibility for timekeeping and serves civilian government agencies as well as its military. But very few civilian agencies ever need to know the time of day with extreme precision and it is not clear whether the military has reserved the most precise measurements for itself as has happened in the case of the military Navstar global positioning system. Even if the time of day is not yet an official secret in Britain, where we all are is information which the Pentagon has classified.

\section{Department of Physics,} University of Auckland, New Zealand
Peter Willis 